\title{
Implementing the Epidemic Diseases Act to combat Covid-19 in India: An ethical analysis
}

\author{
RAKESH PS
}

\begin{abstract}
Many states in India have invoked the provisions of the Epidemic Diseases Act, 1897, as a major tool in the fight against the Covid19 pandemic. The current review attempts to discuss the ethical challenges in implementation of the Epidemic Diseases Act, 1897, to combat Covid19 in India. Implementation of the Act in India has exposed its major limitations. It remains merely as a 'policing-Act with no emphasis on coordinated and scientific responses to outbreaks and without provisions for protecting the rights of citizens. The Epidemic Diseases Act in its current form has the potential to cause more harm than good. Furthermore, the Epidemic Disease (Amendment) Bill, 2020, has not addressed any of these concerns. There is need for a rightsbased, peoplefocused and public healthoriented law in India to deal with epidemics.
\end{abstract}

Keywords: pandemic, Epidemic Diseases Act, policing, Covid19, ordinance

\section{Introduction}

Following the increasing numbers of Covid-19 cases in India, on March 11, 2020, the Ministry of Health, Government of India, asked the states to invoke the provisions of the Epidemic Diseases Act, 1897. Most Indian states have invoked their powers under the Act to combat Covid-19 (1-5). As calls for government action grew, the Epidemic Diseases Act has become a subject of debate.

On April 22, 2020, the Government of India announced the promulgation of The Epidemic Diseases (Amendment) Bill, 2020, to amend the Act, adding provisions to punish those attacking doctors or health workers, and this was recently passed by both houses of Parliament (6).

The current review attempts to discuss the ethical challenges arising in the implementation of the Epidemic Diseases Act, 1897 to combat Covid-19 in India.

\section{The Epidemic Diseases Act, 1897: Limitations in the current scenario}

Author: PS Rakesh (rakeshrenjini@gmail.com), Visiting Faculty, Centre for Public Health, Amrita Institute of Medical Sciences, Kochi, 682041 INDIA; Bernard Lown Scholar, Department of Global Health and Population Medicine, Harvard T H Chan School of Public Health, Boston, USA.

To cite: Rakesh PS. Implementing the Epidemic Diseases Act to combat Covid-19 in India: An ethical analysis. Indian J Med Ethics. 2021 Jan-Mar; 6(1) NS: 13-17.DOI: 10.20529/IJME.2020.129.

Published online first on December 15, 2020.

Manuscript editor:Veena Johari

(c) Indian Journal of Medical Ethics 2020
The Epidemic Diseases Act, which was promulgated to tackle the epidemic of bubonic plague in colonial India, was passed in 1897 with the aim of better preventing the spread of "dangerous epidemic diseases". The Act has four sections. The first section explains the title and scope of the Act. The second section gives powers to the governments to take special measures and formulate regulations that are to be observed by the people to contain the spread of disease. Penalties for violating the regulations, in accordance with Section 188 of the Indian Penal Code have been described in Section 3 of the Act, and legal protection for the implementing officers acting under the Act has been explained in Section 4 (7).

The limitations of the Act have been described by this author in detail in an earlier paper (8). Implementation of the Act during the pre-independence era witnessed its enormous potential for abuse. The colonial Epidemic Diseases Act 1897 reflects the standards of governance and scientific development that prevailed in the 19th century, which is not in line with the contemporary political scenario and the current scientific understanding of outbreak prevention and response. The Act is purely regulatory in nature and lacks a specific public health focus; besides being silent on ethical issues or human rights breaches that come into focus during its implementation.

As an attempt to address these concerns regarding the Act of 1897, a draft Public Health (Prevention, Control and Management of Epidemics, Bio-Terrorism and Disasters) Bill of 2017 was proposed (9). The draft bill laid down a clear definition of "epidemic". It also detailed the potential responses by a state government or administration of any Union Territory or district and the central government. Provisions for appeal in favour of potential victims have been included. Even though it had major drawbacks, this draft Bill was an attempt in the right direction to address some of the limitations of the Epidemic Diseases Act, 1897 (10). However, the Bill did not get tabled in Parliament, the reason for which is not clear.

\section{Invoking the Epidemic Diseases Act, 1897, against the Covid19 pandemic}

Most of the states in the country have invoked the Epidemic Diseases Act, 1897, to combat Covid-19 (1-5). The functioning of schools, colleges, cinema halls, and public swimming pools was suspended under the provisions of the Act. All private hospitals were asked to start "flu corners", and to record information regarding the travel and contact history of patients, and decide on quarantine/ isolation as per guidelines. The Act conferred powers on surveillance personnel to carry out inspection, enquiry and examination by entering any premises and to place infected persons in quarantine or isolation. There were provisions for enforcing cooperation by coercive actions against an owner or occupier or individual who did not comply with the directions of the surveillance personnel. Nobody was allowed to use any print or electronic 
medium to share any information regarding Covid-19 without the permission of government to avoid the spread of rumours or unauthenticated information regarding Covid-19. The Act also empowered the relevant authority to carry out containment measures in defined geographical areas including sealing, banning entry and exit, and banning vehicular movement. Many states have made the use of facemasks mandatory under the provisions of the Epidemic Diseases Act. The Act was also used by many states to seal state borders, restricting public and private transport, inspecting or quarantining persons arriving in the state by air, rail, road, or sea, restricting the congregation of persons in public or religious spaces, and prohibiting and restricting the functioning of shops and commercial establishments.

\section{Ethical analysis of implementation of the Epidemic Diseases Act}

Legal and ethical norms go hand in hand $(11,12)$. Here I discuss the ethical aspects of implementation of the Epidemic Diseases Act, 1897, against Covid-19, using the ethical framework proposed by Nancy E Kass (11) and the public health and human rights framework of Gostin and Lazzarini (12) with contextual customisation.

\section{What were the public health goals for invoking the Act?}

On January 30, 2020, the World Health Organization (WHO) declared Covid-19 a public health emergency of international concern, WHO's highest level of alarm. On March 11, when the Government of India (Gol) advised invoking the Epidemic Diseases Act, some 37,364 cases had been reported outside China in 113 countries, including 1130 deaths. Countries like Korea, Italy, and Iran had more than 5000 cases each. At the time, India had 60 confirmed cases (13)

In a country with a huge population and with inherent weaknesses in the health system, tackling epidemics is a complex task. States across the world were employing farreaching measures to handle the coronavirus outbreak. It could not be fully accomplished without a well-thought-out system with strong statutory backing. Prevention and control of epidemics requires protective measures against avoidable risks, and an effective and prompt response. The Epidemic Diseases Act was the only specific legislation in existence on the subject, therefore invoking it was justifiable.

\section{What evidence was available regarding effectiveness of the intervention?}

What was the evidence of the effectiveness of the Act, to justify the invoking its provisions? The greater the burdens imposed by an intervention in terms of constraints on individual autonomy and liberty the stronger the evidence must be to demonstrate that an intervention will achieve its goals. There was little scientific evidence demonstrating the effectiveness of legal enforcements for dealing with pandemics. What was available was only a few prior experiences of enforcing regulatory measures during pandemics, and that mainly from the colonial period.

For managing Covid-19, strict legally-backed lockdown measures were implemented in China and South Korea. Countries like the United States (US), the United Kingdom (UK), France, etc, were reluctant to impose stringent restrictions initially; but the rapid increase in cases later led to their adoption of increasingly severe measures to prevent health systems from collapsing. In such circumstances, with an obligation to protect populations from reasonably foreseeable threats, state-imposed restrictions under the available laws, even in the absence of complete scientific information, may be justified.

\section{What burdens were imposed by implementation of the Act?}

Stringent enforcement of the law to fight a pandemic has to be balanced by checks on the use of power, to protect the rights of individuals. The Epidemic Diseases Act, 1897, does not provide for procedural guarantees against the abuse of power in interference with the rights of citizens.

Many reports suggest that the authorities used their powers under the Epidemic Diseases Act for publicly sharing the lists of infected patients, and for arresting and booking persons for acts like: spreading fake news about the disease, not disclosing information, not following quarantine or isolation norms, and for going about to meet their basic needs in breach of the lock-down (14-19).

Enforcing quarantine and isolation were the most widely used applications of the Act. During implementation, personal autonomy was curtailed on the presumption of beneficence towards the wider public. Here, the states have introduced compulsory isolation, as a means to prevent further harm to their people (duty of non-maleficence), by isolating the affected or quarantining those exposed to infection (duty of beneficence). However, provision for addressing the medical, non-medical and psychological needs of people in quarantine was not made in many places. The Act does not speak about the consent of the infected person. Forceful quarantine and isolation have led to inconvenience and distress to individuals, even resulting in suicides in many places (20). In many institutional quarantine facilities, the congregation of many people in a confined space led to the transmission of disease within the setting (21). Individuals were exposed to risks causing inadvertent harm, which goes against the principle of doing no harm to the individual; and many suffered adverse consequences. How can they be compensated for the lack of beneficence or non-maleficence?

Mandatory notification of disease and the follow up public health actions led to breach of confidentiality in many instances. Governments used the provisions of the Epidemic Diseases Act to obtain, process, maintain and use sensitive personal data; track locations; employ contact tracing measures without any data protection framework in place $(14$ 22). Surveillance and contact tracing raise potential privacy concerns, especially since data collection is mandatory and the data of individuals are identifiable and, in many cases, were made publicly available. Lists of Covid-positive individuals, route maps of Covid-positive cases published for contact tracing, public notices at houses of quarantined individuals breached their privacy and confidentiality. In many places, contact tracing, which is a scientific process, was entrusted to the police rather than to trained health professionals (23). The community often harbours an instinctive distrust of the police which was aggravated by their handling of the data obtained during contact tracing, without any respect for privacy, as in a criminal investigation (23).

Section 4 of the Epidemic Diseases Act protects those acting in good faith under the provisions of the Act from any legal 
proceeding. There are many instances where the unchecked powers given under the Act became a bulwark for police brutality with risks to citizen's rights (14-24). Citizens were reportedly assaulted and subjected to harsh treatment when they went out to purchase their basic necessities, or even opened their small grocery shops. Some instances were reported where the Act was used to suppress political or personal opponents $(16,19)$. Since the provisions of the Act were broadly phrased, those sometimes resulted in arbitrary actions. For example, a news reporter was arrested for writing against corruption in the public distribution system (19).

The principle of justice was put at risk when the authorities targeted public health interventions only at certain groups. Many states publicly made declarations about ethnic groups that were stigmatising and otherwise harmful. There were reports of strong protests by communities for stigmatising them with provisions under the Act (25). Social harms result if social stereotypes are created or perpetuated, such as stating that only certain segments of the population are the causes of disease spread. In many places, non-resident Indians and nonresidents of states faced stigma and discrimination (26).

Using excessive force has shown a negative impact on community participation. It has even led to the emergence of disorder in some places $(16,25,27)$. Cohesion has given way to conflict between society and the authorities. Published reports show that several communities have become hostile to "strict measures" for epidemic control $(25,27)$, and moved away from testing and disclosing symptoms out of fear (28). Also the prevalent atmosphere of fear led to even greater stigmatisation and discrimination.

The Act is silent on the government's responsibilities during a pandemic. It is felt that the Act has been used by the authorities in several places as a short cut to get things done instead of adopting the least restrictive measures like counselling, education or ensuring the active participation of communities. Invoking of the Epidemic Diseases Act also inclined the authorities towards a regulatory approach, rather than one of educating and empowering citizens to actively participate in the fight against the disease.

\section{Are alternative approaches possible?}

Ethically, an approach that poses fewer risks to autonomy and justice should be chosen. The Siracusa Principles set out the basis for an international law in which human rights may be restricted in view of a public health emergency. The primary principle is that state restrictions are only justified when they are:

- directed towards a legitimate objective of public interest;

- absolutely necessary in a democratic society to achieve the objective;

- least restrictive in achieving the objective;

- based on scientific evidence;

- neither arbitrary nor discriminatory in application, and of limited duration;

- respectful of human dignity; and

- subject to review (29).
When we look at the implementation of the EpidemicDiseases Act during the Covid-19 times in India, many of the above principles were not met.

The least restrictive measures should be taken to control the spread of the disease, and these measures should be voluntary to the greatest possible extent. Medical and social needs of the persons whose movement was restricted must be met, and the application of restrictions should be equally fair and transparent for all the people. Where compliance with physical distancing or quarantine or isolation is directly in conflict with meeting basic needs, societal harms are inevitable and need to be mitigated. The necessary precautions should have been taken to avoid discrimination and stigmatisation during quarantine, isolation or containment. All legal enforcements should go hand in hand with informed and transparent public communication strategies. If properly informed, most people will follow their instinct to stay safe. Strategies need to be implemented to address the public's lack of scientific understanding of risks, if any. Good and effective communication strategies should have been adopted through official channels to fill the information vacuum in which misinformation proliferates.

\section{How can the benefits and burdens of coercive policies be fairly balanced?}

If burdens due to implementing coercive acts are more than the actual intended benefits, then such interventions should never be attempted. Some suggestions for ensuring that the benefits are more than the actual burdens are as follows:

- Programmes that are coercive must be kept to a minimum and should be implemented only if there is a clear public health need and good data demonstrating effectiveness.

- The community has to be engaged in a democratic process to determine which interventions it wants its government to maintain, and how restrictive the measures should be. Open discussion with the community is to be promoted regarding the restrictive measures, and why such benefits cannot be obtained through more liberal methods. Different states and communities ma decide differently about which public health activities are appropriate and which are overly burdensome. Different communities may adopt locally customised public policies, based on their own balancing of benefits and burdens.

- Ethical analysis of the implementation of legal measures during a pandemic strengthens our reasoning and we can then recommend interventions on the basis of facts and not mere beliefs. The participation of the community in the process will help to identify the potential threats many groups will face, especially the vulnerable segments. Any fight against pandemics is possible only through community ownership and for that public trust is most important. If legal enforcements leads to public distrust, then it can cause more harm than good during the fight against a pandemic.

- Every legal enforcement by the government has to pass the test of protection of the right to privacy which is a fundamental right. Even in the case of a notifiable disease, the authorities have to keep the information confidential. The protection of civil rights during implementation of the Epidemic Diseases Act could have improved population health. For example, protection of privacy and against discrimination for individuals with stigmatised conditions may 
encourage them to seek testing and treatment. If the public health laws protect civil rights, it is likely that the trust and participation of citizens will also increase.

- The pandemic has also generated the demand for a robust law that provides for the collection, processing, usage and retention of sensitive personal data, efficiently balancing the right to privacy of an individual with public interest. Policies which are consistent with the preservation of human dignity and those showing equal respect for the interests of all members of the community will ensure social justice.

\section{The Epidemic Diseases (Amendment) Bill 2020}

Citing the multiple incidents of violence against doctors and hospitals in India, there has been a long-standing demand from the professional medical associations for protective legislation. The Covid-19 pandemic exacerbated the violence, harassment and discrimination against healthcare workers, mainly due to fear and misinformation that spread in the community. As healthcare workers are on the frontlines during the pandemic, government declared its commitment to protecting them by promulgating the Epidemic Diseases (Amendment) Bill, 2020.

One of the important provisions in the Amendment Bill is that it defines the terms "healthcare service personnel","property" and "act of violence", before stating that "no one shall indulge in any act of violence against a healthcare services professional or cause any damage or loss to any property during an epidemic." The Bill allows for up to seven years of jail for attacking doctors or health workers (including community health volunteer workers). Such offenses have been made cognisable and non-bailable (6).

The penalty provisions prescribed in the Amendment Bill are more stringent than in the Act, in terms of years of imprisonment and penalty amount. The Amendment Bill has also expedited the investigation process, which has to be completed within 30 days, and the burden of proof has been reversed, with the accused being considered guilty until proven innocent. The Amendment Bill provides a broad definition of the term "violence" to include harassment which affects the living or working conditions of healthcare personnel. This is relevant while healthcare personnel are facing stigma due to their work, where they were being forced to vacate their accommodation by land lords or by residents' associations. The Bill also has provisions to charge the guilty to remit twice the market value of the damaged property as compensation for damaging the assets of healthcare staff including vehicles and clinics (6).

The Amendment Bill clearly states that the violence or damage has to be done "during an epidemic", thus making it highly contextual and limited. However, instances of violent confrontations between doctors and the public are neither a recent phenomenon nor do they occur only as a result of an epidemic. Ensuring the safety of healthcare personnel has to be guaranteed by law, not only in the context of epidemics, but during normal times as well.

\section{Conclusion}

Legal frameworks are important for the prevention and control of major outbreaks of infectious diseases. Implementation of the Epidemic Diseases Act, 1897, to fight Covid-19 in India has exposed its major limitations. These limitations include not mentioning the responsibilities of Government during epidemics, not establishing mechanisms to protect the rights of citizens, not clearly delineating the roles and responsibilities of various agencies and departments in combating epidemics; and not having a regulatory authority or appellate mechanism to address grievances about its implementation. Remaining merely a "policing" act with no emphasis on coordinated and scientific responses to deal with outbreaks, the Epidemic Diseases Act, 1897, in its current form has the potential to cause more harm than good. The current amendment has not addressed any of these concerns. It tried to address a major problem related to the safety of healthcare personnel with a narrow lens. There is a need for an integrated, comprehensive, actionable and relevant legal provision for the control of outbreaks in India that should be articulated in a rights-based, people-focused and public health-oriented manner.

\section{References}

1. Government of Karnataka. The Karnataka Epidemic Diseases COVID-19 Regulations, 2020. N0 HFW54 CGM 2020. Bangalore. 2020 Mar 11 [cited 2020 Nov 10]. Available from: https://www.mzv.cz/public/43/bd/ e3/3916986_2331956_Karnataka_Epidemic_Act.pdf

2. Government of Delhi. The Delhi Epidemic Diseases COVID 19 Regulations, 2020. No F 51/DGHS/PH-IV/ COVID-19/2020 M. New Delhi. 2020 Mar 12[cited 2020 Nov 10]. Available from: http:// health.delhigovt.nic.in/wps/wcm/connect/

146af7004d87f91c96a2f7982ee7a5c7/Epedimic+Act.pdf? MOD=AJPERES\&Imod $=-$

762064770\&CACHEID=146af7004d87f91c96a2f7982ee7a5c7

3. The Jharkhand Gazette. The Jharkhand State Epidemic Disease COVID 19 Regulations, 2020. No 178. Ranchi. 2020 Apr 24 [cited 2020 Nov 10]. Available from: https://lexcomply.com/rsjadmin/news/ 202004302625Notification\%20Ref.\%20No.\%2061\%20(13)\%20Jharkhand\%20State\%20Epidemic\%20Disease\%20(COVID19)\%20Regulations,2020.pdf

4. Government of Maharashtra. The Maharashtra COVID-19 Regulations 2020. No-Corona 2020/CR-58/ Arogya-5. Mumbai. 2020 Mar 14[cited 2020 Nov 10]. Available from: https://www.maharashtra.gov.in/Site/ Upload/Acts\%20Rules/Marathi/ Korona\%20Notification\%2014\%20March\%202020....pdf

5. Government of Meghalaya. The Meghalaya Epidemic Diseases COVID19 (Fifth Amendment) Regulations 2020. No 68/2020/38 Shillong:GoM; 2020 Mar 19 [cited 2020 Nov 11]. Available from: http:// meghealth.gov.in/covid/Notification\%20-

\%205th\%20Amendment\%20of\%20MED\%20COVID\%20Regulations\% 202020.pdf

6. Ministry of Law and Justice. The Epidemic Diseases Amendment Ordinance 2020. New Delhi. No 5 of 2020.2020 Apr 22[cited 2020 Nov 10]. Available from: http://egazette.nic.in/WriteReadData/ 2020/219108.pdf

7. Government of India. The Epidemic Diseases Act of 1897. Act No 3 of 1897 [cited 2020 Oct 4]. Available from: http://legislative.gov.in/sites/ default/files/A1897-03.pdf

8. Rakesh PS. The Epidemic Diseases Act of 1897: Public health relevance in the current scenario. Indian J Med Ethics. 2016 Jul-Sep; 1 (3): 156-60

9. Government of India. Draft Public Health (Prevention, Control and Management of Epidemics, Bio-terrorism and Disasters) Bill, 2017. New Delhi: Gol; 2017[cited 2020 Oct 3]. Available from: https:// www.prsindia.org/uploads/media/draft/ Draft\%20PHPCM\%20of\%20Epidemics,\%20BioTerrorism\%20and\%20Disasters\%20Bill,\%202017.pdf

10. Bahurupi Y, Mehta A, Singh M, Aggarwal P, Kishore S. Epidemic diseases act 1897 to public health bill 2017: Addressing the epidemic challenges. Indian J Public Health. 2020;64(6):S253-511.

11. Kass NE. An ethics framework for public health. Am J Public Health. 2001 Nov 1;91 (11): 1776-82.

12. Gostin LO, Lazzarini Z. Human rights and public health in the AIDS pandemic. New York, NY: Oxford University Press; 1997.

13. World Health Organization. Rolling updates on coronavirus disease (COVD-19). Date unknown [cited 2020 Oct 7]. Available from: https:// www.who.int/emergencies/diseases/novel-coronavirus-2019/eventsas-they-happen

14. Sharma BSS. Can quarantined, infected people's details be published under Epidemic Diseases Act? Wire.in. 2020 Apr 05[cited 2020 Oct 8]. 
Available from: https://thewire.in/tech/epidemic-diseases-actpersonal-details

15. HT Correspondent. Police crackdown on Covid-19 'misinformation' activists concerned. Hindustantimes.com. 2020 Apr 30[cited 2020 Oct 8]. Available from: https://www.hindustantimes.com/india-news/ about-500-cases-lodged-in-india-for-social-media-posts-on-covid-19/ story-PBaxt7oNs9ldPNUCVRiUUM.html

16. Mahaprashasta AA. Outrage as Adityanath govt uses Epidemic Diseases Act to arrest CAA dissenter. Wire.in. 2020 Mar 27[cited 2020 Oct 8]. Available from: https://thewire.in/rights/ashish-mittalepidemic-act-uttar-pradesh

17. Rabi MA. Social worker assaulted by cop, booked under Epidemic Act. Indianexpress.com. 2020 May 5[cited 2020 Oct 8]. Available from: https://www.newindianexpress.com/states/tamil-nadu/2020/may/13/ social-worker-assaulted-by-cop-booked-under-epidemic-act2142693.html

18. Subramaniam L. 4 booked in TN for violating home quarantine, could face up to 3.5 years in jail. Week.in. 2020 Mar 25[cited 2020 Oct 8]. Available from: https://www.theweek.in/news/india/2020/03/25/4booked-in-tn-for-violating-home-quarantine-could-face-up-to-35years-in-jail.html.

19. Thirumurthy P. SimpliCity website founder booked under Epidemic Diseases Act in Coimbatore. Newsminute.com. 2020 Apr 24[cited 2020 Oct 8]. Available from: https://www.thenewsminute.com/article/ simplicity-website-founder-booked-under-epidemic-diseases-actcoimbatore-123230. [Cited on October 8, 2020]

20. Dsouza DD, Quadros S, Hyderabadwala ZJ, Mamun MA, Aggregated COVID-19 suicide incidences in India: Fear of COVID-19 infection is the prominent causative factor. Psychiatry Res. 2020; 290: 113145

21. Thakker T. Covid-19 spread: Poor conditions of quarantine facilities come into focus in India. Economictimes.indiatimes.com. 2020 Mar 21[cited 2020 Oct 8]. Available from: https:// economictimes.indiatimes.com/news/politics-and-nation/poorconditions-of-quarantine-facilities-come-into-focus/articleshow/ 74738682.cms

22. Parthasarathy S. Privacy concerns during a pandemic. Hindu.com. [newspaper on the internet]. 2020 Apr 29[cited 2020 Oct 8. Available from: https://www.thehindu.com/opinion/op-ed/privacy-concernsduring-a-pandemic/article31456602.ece.

23. Kattakayam JJ. When contact tracing becomes policing. The Times of India. [newspaper on the internet] 2020 Aug 20[cited 2020 Oct 8]. Available from: https://timesofindia.indiatimes.com/blogs/jibberjabber/when-contact-tracing-becomes-policing/.

24. Scroll Staff. Coronavirus: Hundreds booked across states for violating restrictions amid lockdown. Scroll.in. 2020 Mar 24[cited 2020 Oct 8] Available from: https://scroll.in/latest/957080/coronavirus-hundredsbooked-across-states-for-violating-restrictions-amid-lockdown.

25. Correspondent. Lockdown violation in Poonthura; people begins protest on street. Mathrubhoomi.com. 2020 Jul 10[cited 2020 Oct 8]. Available from: english.mathrubhumi.com/news/kerala/lockdownviolation-in-poonthura-people-begins-protest-on-streets-1.4894876

26. Sanjeev D. Gulf, Mumbai returnees feel stigmatised. Timesofindia.indiatimes.com. 2020 May 16[cited 2020 Oct 8]. Available from: http://timesofindia.indiatimes.com/articleshow/75765172.cms? utm_source=contentofinterest\&utm_medium =text\&utm_campaign= cppst.

27. Parasthe G. Anandnagar rises in protest against containment, cops use force to quell it. Punemirror.indiatimes.com. 2020 Jun 09[cited 2020 Oct 8]. Available from: https://punemirror.indiatimes.com/pune/civic/ anandnagar-rises-in-protest-against-containment-cops-use-force-toquell-it/articleshow/76270964.cms.

28. Ramakrishnan S. In Madurai, people reluctant to test now: Doc. Timesofindia.indiatimes.com. 2020 Sep 30 [cited 2020 Oct 8]. Available from: http://timesofindia.indiatimes.com/articleshow/78395321.cms? utm_source=contentofinterest\&utm_medium=text\&utm_campaign= cppst.

29. American Association for the International Commission of Jurists. Siracusa Principles on the Limitation and Derogation of Provisions in the International Covenant on Civil and Political Rights (1984) (Annex, UN Doc E/CN.4/1984/4)[cited 2020 Oct 8]. Available from: https:// www.icj.org

\title{
Covid-19 vaccine trials and ethics: Protection delayed is protection denied
}

\author{
T JACOB JOHN, DHANYA DHARMAPALAN
}

\section{Abstract}

The Covid-19 pandemic is raging, taking a heavy toll of lives and livelihoods. The need for safe and effective vaccine(s) is urgent. Vaccine research has progressed rapidly and a few vaccine candidates have passed trial Phases 1 and 2, confirming reasonable safety and immunogenicity parameters. They are ready for large scale Phase 3 trials to quantify protective efficacy, if any, and to detect uncommon but serious adverse effects, if any.

Author: T Jacob John (tjacobjohn@yahoo.co.in), Retired Professor, Christian Medical College, Vellore, Tamil Nadu 632002 INDIA; Dhanya Dharmapalan (corresponding author - drdhanyaroshan@gmail.com), Consultant in Pediatric Infectious Diseases, Apollo Hospitals, CBD Belapur, Navi Mumbai. Maharashtra, INDIA.

To cite: John TJ, Dharmapalan D. Covid-19 vaccine trials and ethics. Indian J Med Ethics. 2021 Jan-Mar; 6(1) NS: 17-20. DOI:10.20529/ IJME.2020.104.

Published online first on October 24, 2020.

Peer Reviewers: Two anonymous peer reviewers

(c) Indian Journal of Medical Ethics 2020
These developments present unprecedented opportunities and challenges, scientific and ethical. Globally hundreds die every day due to Covid-19, and emergency/compassionate use of vaccine candidates that are ready for Phase 3 trials are likely to save lives. We perceive an ethical imperative to allow such an vaccination for those at high risk of death who voluntarily make such informed choice "for them protection delayed will be tantamount to protection denied.

Keywords: Covid-19, vaccine, vaccine trials, emergency use

\section{Introduction}

During the relentless march of the Covid-19 pandemic, globally we have faced the unprecedented problem of the highly contagious SARS coronavirus-2 (SARS-CoV-2) spreading like influenza. The world is prepared for an influenza pandemic, with global networks of laboratories in every continent constantly collecting virus strains, for the detection of any genetically shifted virus capable of seeding a 